\title{
Are we there yet? On a journey towards more contextually relevant resources in speech-language therapy and audiology
}

\begin{abstract}
Audiologists and speech-language therapists working in developing contexts like South Africa have the opportunity to address a range of needs through their research. One of these needs is the development of assessments and therapy materials that are appropriate for their clients' particular language needs and cultural background. This editorial paper aims to introduce original research in speech-language therapy and audiology, which has been carried out in South Africa and other developing contexts and is presented in this volume of the journal. In addition we suggest that while the focus of much research is on the destination or end product that is developed, there is a need to share the methodologies that are used to reach that goal so that more research can be carried out by a wider pool of students, researchers and clinicians. We describe some of the methods that we have used in our research - often in small scale projects with budgetary constraints, which would be feasible for clinicians in their routine clinical contexts. Our hope is that others can build on these approaches, critique and share their own strategies for the ultimate advancement of the professions in southern Africa.
\end{abstract}

Keywords: cross-cultural adaptation, methodology, resources, Delphi, isiXhosa, Afrikaans

S Afr J CD 2013;60:2-9. DOI:10.7196/SAJCD.256

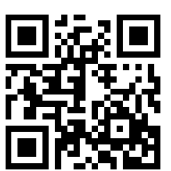

Speech-language therapy and audiology are relatively new and relatively small professions in South Africa and are beset with a host of challenges. Some of these challenges include perceived low priority and low relevance against the backdrop of a quadruple burden of disease, lack of awareness about the profession and its scope, and the fact that language and communication lie at the heart of our work; yet in many cases the mismatch between therapists and audiologists and their clients in terms of language creates almost insurmountable barriers in providing equitable service delivery. Many papers that have been published in this journal (Barrat, Khoza-Shangase \& Msimang, 2012; Kathard, Naude, Pillay \& Ross, 2007; Pascoe \& Norman, 2011; Penn, 2007) and in others (Penn, 1998; Southwood \& van Dulm, 2013; Swanepoel, 2006; Maphalala, Pascoe \& Smouse, 2013) detail this context and the challenges of providing a populationbased service delivery. Authors such as Kathard et al. (2007) and Penn (2007) focused on the need for more research, as well as research that has greater relevance in our context. Barrat et al. (2012) looked primarily at clinical encounters and the use of untrained personnel as translators and interpreters. Southwood and Van Dulm (2013) focused on development of multilingual therapy materials, and Maphalala et al. (2013) on isiXhosa speech assessment.

One of the more tangible aspects of the challenges faced is that of a lack of contextually relevant assessment and therapy materials. In 2011 our editorial introduction (Pascoe \& Norman, 2011) explored this in detail, while that entire volume (SAJCD, volume 58) showcased original South African research that was carried out with a view to furthering the development agenda of speech-language therapy and audiology. In this volume of SAJCD, Gonasillan, Bornman and Harty (2013) describe their work with toddlers from a range of different language and cultural backgrounds in South Africa and the way in which the Language Development Survey (LDS) (Rescorla, 1989), a widely used checklist with demonstrated validity and reliability, was adapted and found suitable for use within the South African context. Detailed and systematic studies of established assessments, such as this one, provide much-needed support for clinicians who may be unsure about which assessments are appropriate for adaptation, and where it may be preferable to devise an assessment 'from scratch'. Another excellent example of contextually relevant intervention material comes from Southwood and Van Dulm and (2012) who have devised a language therapy tool kit specifically for use with older children in the South African context who speak English and/or Afrikaans. They presented this at the recent SASLHA conference held in Bloemfontein in September 2013.

Of course, materials development or adaptation is not the only priority for the professions in South Africa. However, the focus on materials development is appealing because it provides a very tangible and practical focus for speech-language therapists (SLTs) and audiologists (As) who want to make a change to their practice with clients and who may wish to become involved in research that will have a direct bearing on their own clinical practice. In this volume, the papers by Wium and Louw (2013) and Erasmus, Schutte, van der Merwe and Geertsema (2013), speak to the need for the professions to respond to the changing contexts in which we work.

Other priorities for the professions include finding and documenting the research designs and methodologies employed. 'Pragmatic approaches' have been described in the literature as research which has relevance to stakeholders and is feasible to be conducted in and used in real-world settings (Glasgow \& Riley, 2013). There is a growing literature base describing pragmatic study designs and the development of pragmatic measures. Pragmatic measures are clearly much needed in our fields.

Single case studies are another potentially useful research design relevant to developing contexts. In the editorial introduction to Child Language Teaching and Therapy, Vance and Clegg (2012) suggested that the single case study can make an important contribution to the evidence base of the profession of speech-language therapy. One of the main messages here was that case studies are achievable for practitioners in their everyday working contexts 'of nurseries, schools and other health and educational services' (p. 257). Vance and Clegg's editorial inspired our current editorial paper; we believe that practitioners have an important role to play in the adaptation and development of materials for use with all our clients in South Africa. The pragmatic approaches and methodologies such as single case studies are achievable for practitioners in their everyday work settings.

The challenges that we face in South Africa are not unique to our context. McLeod, Verdon and Bowen (2013) recently published a paper detailing the development of a position paper to guide SLTs in managing children's speech in multilingual contexts. In this paper, the five phases that were followed in order to develop the position paper are detailed: a face-to-face workshop, creation of the initial draft, online panel discussion, thematic analysis, moderation and finalisation. The paper was developed by 57 members of the International Expert Panel on Multilingual Children's Speech who represented 33 different countries. Of course, the final product will be of great interest to SLTs and As working in southern Africa (http://www.csu.edu.au/research/ multilingual-speech/position-paper) and has close relevance to the topic under discussion here. What is also interesting and inspiring about McLeod et al.s (2013) paper is the careful detailing and description of the way in which the expert panel was formed and the journey that was undertaken to reach the ultimate destination of the position paper. It is a journey that could be undertaken by different groupings in different contexts to address different issues.

We aim to describe some of the research methods that can be used by clinicians to add to the body of contextual knowledge. The work we describe is not necessarily an example of best practice, but 
rather modest examples aimed to inspire and empower practitioners. Replications of small-scale studies across different settings and different individuals will increase the external validity of these projects. Ultimately publication should occur to ensure that the work is shared and read by practitioners. All too often development projects have fallen by the wayside because the ultimate destination was not reached, and valuable methodological lessons are lost. The methodologies described here could all be used in a variety of different projects and adapted for the particular aim of a study. They all require few resources and are simple to execute. They are 'pragmatic' in the sense of being important and relevant for stakeholders as well as being time- and cost-effective.

The Delphi technique is a research approach that has been widely used in social sciences, and increasingly in health sciences (Keeney, Hasson \& McKenna, 2011). It involves the formation of an expert panel or panels whose members have specific knowledge of a particular topic. The panel is tasked with reaching consensus on a particular topic or set of questions. Multiple rounds are often needed in order for the panel to carry out a problem-solving or decision-making remit. Originally developed for military settings in which the demands of a task exceeded a single person, the Delphi technique has been widely adapted for a range of very different purposes. In our research we have used this approach in two different ways: $(i)$ to reach consensus regarding the selection of stimuli (words and pictures) which were needed for use in a pilot version of an isiXhosa speech assessment for children, and (ii) to reach agreement about the translation of items for an audiology assessment.

Maphalala (2012) convened a Delphi panel as part of a larger study which aimed to develop a single-word-picture naming assessment in order to collect preliminary data about the typical development of isiXhosa speech (see Maphalala et al., 2013). The objectives of the panel were to arrive at consensus regarding the stimuli (single words and pictures) chosen for the assessment. The panel was presented with a draft list of words. The process was undertaken to ensure that all words included were (i) culturally appropriate, (ii) age-appropriate for the children in question, and (iii) that the assumed pronunciation and meaning were also correct. There were five participants on the panel chaired by the researcher. Two participants (females) were firstlanguage isiXhosa speakers. They were preschool educators who are familiar with young children. Two participants (one male, one female) were academics at the university working in African languages. These participants were not first-language isiXhosa speakers but were fluent in that language and had studied it. Both of them are parents of young children. Finally, the fifth participant was an undergraduate student of speech therapy who had isiXhosa as her first language. The panel was chosen because of their innate and learnt knowledge of isiXhosa and because of their interest and knowledge of young children's speech and language development.

A checklist was devised for the purpose of the panel (Table 1). It contained words that had been selected by the researcher and were thought to include all the speech sounds (consonants and vowels) and word shapes that appear in the isiXhosa phonetic inventory. The words were judged to be age-appropriate for preschool children as well as able to be represented by a picture. However, these judgments of the researcher required further validation from the panel.

The purpose of the study was explained and checklists were distributed. An explanation of the word-checking process was given. Terms were defined (e.g. what is meant by culturally appropriate) and participants were given the opportunity to ask questions about the checklist. Participants were given time to fill out the checklist, a process that took approximately 20 minutes. They were urged to refrain from any discussions until the checklists were completed. During this time, no audio recordings were taken. Recording began when the discussion was started. In order to analyse the wordlist, each word was read out aloud by one of the first-language speakers. Participants were given the opportunity to comment on words they found inappropriate, i.e. if a word received any 'no's', it was considered problematic and was discussed. Participants who raised issues with words were asked to comment on what the exact problems were. This was discussed among the group and if there was agreement, a new word was suggested by the panel. This was checked in terms of the three criteria and if it passed, it was then used as part of the wordlist.

Of the 65 words initially in the list, 54 were found appropriate in all three categories. The main reason for inappropriate words was that they were not age-appropriate vocabulary. Table 1 provides examples of some of the problematic items.

The development of a preliminary isiXhosa speech assessment was a challenging process that required ongoing validation and development. Using the expert panel at this early stage of the research was helpful in validating some of the decisions that had been made, and also in flagging potentially problematic items.

Another example of the use of a Delphi panel comes from audiological literature and illustrates how this type of approach can be used in translation work in our field. Rogers et al. (2011) focused on dizziness, a common occurrence in the general and medical population. Frequently patients and clinicians are at odds regarding symptom definition, e.g. there are 26 different English language words for 'dizziness', not all of which suggest the quality of the complaint and especially not a possible vestibular origin. Lack of understanding becomes compounded when managing symptom description across a range of languages. The original English language Vertigo Symptom Scale ((VSS), Yardley, Masson, Verschuur, Haacke \& Luxon, 1992) is a validated self-assessment scale, which explores aspects of vertigo and associated symptoms of anxiety, and has been widely used in research and clinical settings.

Translated measures should be validated; however, there is evidence in the literature that both the quality and validation of translated instruments are variable (Sousa \& Rojjanasrirat, 2011). Delphi panels offer a time-efficient, low-cost and effective way to reach consensus and refine translations of instruments. Panels may be facilitated electronically which may offer an additional advantage in that members do not influence one another in the way that may occur in focus groups - as in Maphalala's (2012) project, for example; but instead can be used to build on the work of all members and reach consensus (Mokkink et al., 2010).

Rogers et al. (2011) used a modified (two-round) Delphi consensus procedure to refine translation of the VSS, as well as to seek opinion regarding Afrikaans words which would capture the essence of the word 'vertigo.' Two first-language Afrikaans-speaking audiology students independently translated the VSS into the target language. Thereafter two panels were selected in preparation for the Delphi consensus procedure. Panel 1 comprised five lay individuals who were first-language Afrikaans speakers. Levels of education ranged from having completed high school (grade 12) to university graduates. Five bilingual healthcare professionals who regularly treated patients with vertigo contributed to panel 2 . Disciplines included audiology, otolaryngology, aviation medicine and psychology. With the exception of the psychologist, all practitioners had received specialised post-graduate training in vestibular disorders and were familiar with the VSS.

The initial two translations into Afrikaans were merged into one as there were no differences between the versions. Translation back into English helped highlight areas of ambivalence, e.g. items in which a choice of words could be used, which in turn formed the basis for discussion with both expert panels. Questionnaires with five-point Likert-scale responses and space for qualitative comments regarding the translation of the VSS were prepared for each panel. Participants in panel 1 responded to questions regarding the language, grammar and vocabulary of translated items. Examples of questions are shown in Table 2 and specifically probe if the meaning of translated items is clear.

Questionnaires were constructed with both positively and negatively phrased constructs in order to cross-check consistency of opinion. The purpose of round one of the Delphi was to:

- Identify items on which there were high levels of agreement regarding the translation. These could be adopted immediately without need for further exploration.

- Give and elicit examples of different words and terminology for the translation from English to seek vocabulary equivalence in Afrikaans. Vocabulary equivalence (Suleiman \& Yates, 2011) involves the selection of words, which capture the essence, and the nuances of the word used in the original. 
Table 1. Example of a checklist used in an expert panel discussion of stimuli items for an isiXhosa speech assessment (based on Maphalala, 2012)

\begin{tabular}{|c|c|c|c|c|c|}
\hline Word & $\begin{array}{l}\text { Culturally } \\
\text { appropriate } \\
\mathrm{Y} / \mathrm{N}\end{array}$ & $\begin{array}{l}\text { Age } \\
\text { appropriate } \\
\mathrm{Y} / \mathrm{N}\end{array}$ & $\begin{array}{l}\text { Correct } \\
\text { meaning } \\
\mathrm{Y} / \mathrm{N}\end{array}$ & Comments/Suggestions & Result/Changes \\
\hline $\begin{array}{l}\text { uloliwe } \\
\text { (train) }\end{array}$ & $\mathbf{Y}$ & $\mathbf{N}$ & $\mathbf{Y}$ & $\begin{array}{l}\text { Children would recognise the picture of the train, } \\
\text { however they are more likely to use the English word } \\
\text { as this is what most adults use }\end{array}$ & $\begin{array}{l}\text { Word has been removed and the verb } \\
\text { /lala/ will be used instead }\end{array}$ \\
\hline $\begin{array}{l}\text { intshebe } \\
\text { (beard) }\end{array}$ & $\mathbf{Y}$ & $\mathbf{Y}$ & $\mathbf{N}$ & $\begin{array}{l}\text { In isiXhosa there is a different word used for beard } \\
\text { and moustache. Children would not be able to make } \\
\text { the correct distinction and would instead say 'indevu' } \\
\text { (moustache) }\end{array}$ & $\begin{array}{l}\text { It was found that isitshixo (key) would } \\
\text { be simpler for children to identify and } \\
\text { name, and this word will be used in the } \\
\text { list }\end{array}$ \\
\hline $\begin{array}{l}\text { idyasi } \\
\text { (coat) }\end{array}$ & $\mathbf{Y}$ & $\mathbf{Y}$ & $\mathbf{N}$ & $\begin{array}{l}\text { This needs to be illustrated as a long coat with a belt } \\
\text { (i.e a trench coat) otherwise they would refer to it as } \\
\text { a jacket }\end{array}$ & $\begin{array}{l}\text { Illustrators were informed of the } \\
\text { necessary specifications }\end{array}$ \\
\hline $\begin{array}{l}\text { khala } \\
\text { (cry) }\end{array}$ & $\mathbf{Y}$ & $\mathbf{N}$ & $\mathbf{Y}$ & Children may say /lila/ which is also to cry & $\begin{array}{l}\text { Word removed from list and the verb } \\
\text { /khaba/ will be used instead }\end{array}$ \\
\hline $\begin{array}{l}\text { ukukrokra } \\
\text { (suspect) }\end{array}$ & $\mathbf{Y}$ & $\mathbf{N}$ & $\mathbf{Y}$ & Word not generally used within this age group & $\begin{array}{l}\text { Word removed and replaced with krazula } \\
\text { (tear) }\end{array}$ \\
\hline $\begin{array}{l}\text { ixesha } \\
\text { (time) }\end{array}$ & $\mathbf{Y}$ & $\mathbf{N}$ & $\mathbf{Y}$ & $\begin{array}{l}\text { Members felt that the children's interpretation of the } \\
\text { word would be incorrect and that children would say } \\
\text { 'watch' instead of time }\end{array}$ & $\begin{array}{l}\text { Word removed and replaced with ixolo } \\
\text { (peel of a fruit) }\end{array}$ \\
\hline $\begin{array}{l}\text { cheba } \\
\text { (shave) }\end{array}$ & $\mathbf{Y}$ & $\mathbf{Y}$ & $\mathbf{N}$ & $\begin{array}{l}\text { At this age, the word is used by the children to refer } \\
\text { to cut/cutting }\end{array}$ & $\begin{array}{l}\text { Word was kept, however will now } \\
\text { represent 'cut' and not 'shave' }\end{array}$ \\
\hline $\begin{array}{l}\text { ingqele } \\
\text { (cold) }\end{array}$ & $\mathbf{Y}$ & $\mathbf{N}$ & $\mathbf{Y}$ & $\begin{array}{l}\text { Children will not be using this word within this age } \\
\text { group }\end{array}$ & $\begin{array}{l}\text { Word removed and replaced with } \\
\text { ingqiniba (elbow) }\end{array}$ \\
\hline $\begin{array}{l}\text { gxotha } \\
\text { (chase away) }\end{array}$ & $\mathbf{Y}$ & $\mathbf{N}$ & $\mathbf{Y}$ & $\begin{array}{l}\text { Not a word used by children at this age. They may } \\
\text { also use a different word (e.g. hamba) or words that } \\
\text { are not culturally/socially appropriate }\end{array}$ & $\begin{array}{l}\text { Word was removed and replaced with } \\
\text { amagxa (shoulders) }\end{array}$ \\
\hline $\begin{array}{l}\text { ingxolo } \\
\text { (noise) }\end{array}$ & $\mathbf{Y}$ & $\mathbf{N}$ & $\mathbf{Y}$ & $\begin{array}{l}\text { Suggested that children may better interpret word in } \\
\text { the plural form; thus it was suggested that word class } \\
\text { be changed }\end{array}$ & Word changed to /baya-ngxola/ \\
\hline
\end{tabular}

Table 2. Examples of (a) questions and (b) feedback sought from panel 1, first-language Afrikaans lay participants. The numerical Likert scale ranges from $1=e k$ stem verseker saam (I strongly agree) to $5=e k s t e m$ glad nie saam nie (I do not agree at all)

a) Examples of questions asked of panel 1(note entire questionnaire designed for the Delphi panels was in Afrikaans):

1) 'A feeling that things are spinning or moving around' is adequately translated through ' $n$ gevoel dat alles draai of in die rondte beweeg (item 1 )

2)The level of the language used in the scale is appropriate for mother-tongue Afrikaans speakers

3) Do you think the term 'vertigo' should stay the same in this Afrikaans translation?

b) Example of the response format used by panel 1; which sought quantitative and qualitative feedback:

$\begin{array}{lllll}1 & 2 & 3 & 4 & 5\end{array}$

Comments:

Suggestions:

Items that are problematic:

- Identify which items were problematic. These items and the suggestions that emanated from them were fed back to both panels in round two.

Panel 2's focus was on the applicability of the translated items to the Afrikaans-speaking patient population. In addition, panel 2 was invited to contribute words commonly used by their patients to describe their symptoms of dizziness. The questionnaire used for panel 2 is shown in Appendix A.

The forward-backward method of translation proved effective with the proposed Afrikaans version submitted for round one of the Delphi, reaching high levels of consensus with both panels. Items which required further refinement were identified by both panels and the combined input from lay and professional groups fed back in round two allowed a tight focus and an abbreviated version of the Delphi to achieve reliable results when the Afrikaans VSS was presented to a patient population (Rogers et al., 2011). Input from a variety of disciplines allowed development of a vocabulary which would be recognised by first-language Afrikaans speakers, patient populations and clinicians.

The panels described by Maphalala (2012) and Rogers et al. (2011) were relatively simple to organise and manage; participants brought a variety of different types of expertise to the groups (different professional backgrounds, parental, tertiary education/academic and preschool education) so that a wealth of information was obtained, and in the case of Maphalala's group (2012) lively debate occurred. The checklists and questionnaires were helpful in structuring and focusing the experts. Weaknesses include the relatively small number of participants in the groups, the fact that not all participants were first-language speakers of the language in question and that the dialects and origins of speakers were not explicitly considered. Authors such as Keeney et al. (2011) and Cialkowska, Adamowski, Piotrowski and Kiejna (2008) caution that Delphi approaches have been revised and adapted so many times that they can end up being very different watered-down forms of the rigorous approach originally intended. For example, Cialkowska et al. (2008) note 
that the original Delphi was characterised by features which include anonymity of responses from panel experts, controlled feedback and a statistical description of responses. The size of the panel used in the research by Maphalala (2012) and Rogers et al. (2011) is also small, compared to the recommended number which literature suggests may range from 10 to over 1 000 participants. However, it should be noted that the literature is clear that increased panel size does not necessarily improve the decisionmaking process or guarantee a more valid outcome (Powell, 2003). The size of the panel may well be dependent on the expertise that is available on a given topic at a given time. Clearly Maphalala's (2012) panel may not meet all the characteristics of a true Delphi - she referred to it as an 'expert panel'. The boundaries between a true Delphi panel and an expert panel convened for pragmatic purposes may be blurred in this type of research. This should not matter if the panel serves its purpose.

In contrast to the Delphi panels described, the process of protocol development involves documenting the methods used in research as the primary aim in order to enable replication in further projects or clinical settings. Fish et al. (2012) devised a protocol for the development of speech processing and production tasks with young children. Working with isiXhosaspeaking children, they found that there were few assessment resources available in this language, and in order to answer their research questions, they needed to develop some isiXhosa assessment tools suitable for their participants. Since the process of devising these assessment materials proved complex, they documented the steps taken and the practical requirements so that others in a similar situation looking to develop stimuli for a specific language, would be able to build on the steps they had taken. The protocol follows the principles of the Stackhouse and Wells $(1997,2001)$ psycholinguistic framework, and the stimuli selection and design principles detailed as part of this framework. In Glasgow and Riley's (2013) paper describing pragmatic measures, they suggest that it is desirable for pragmatic approaches and measures to be related to a theoretical model, which can help in understanding and interpreting findings and ultimately advance scientific understanding. The protocol details three tasks: naming, repetition and auditory discrimination. The children who participated in this study were three 2-year-old children who were acquiring isiXhosa as their first language and attended a crèche in Nyanga, Cape Town. The results of the tasks carried out are described by Fish et al. (2012). The protocol is presented in Figure 1.

The single-word naming list (from Maphalala, 2012) was used as the starting point for the development of the tasks. Children were asked to name simple pictures of everyday items such as ball (ibhola), head (intloko), cat (ikati) and money (imali). Where children could not name words because of vocabulary limitations, they automatically defaulted on the naming task and responses were elicited using a repetition format. Items that were spontaneously named were analysed in terms of speech accuracy and how closely they resembled adult target productions. Additional words were then selected for the repetition task, and these included a mix of words that were accurately and inaccurately produced. Children may struggle with repetition tasks for a variety of reasons and having different stimuli to repeat (unknown words which are effectively nonwords, words which a child knows but cannot yet produce, and words which a child knows and can produce in an adult-like way) may help a clinician to determine the nature of the underlying difficulties.

The auditory discrimination task used an $\mathrm{ABX}$ protocol, a simplified auditory discrimination task appropriate for 2-yearolds. This type of task does not require the participants to understand the concepts of 'same' and 'different' as many tests of auditory discrimination require. In the $\mathrm{ABX}$ task, children were confronted with their own error and the correct target production, and asked to discriminate between the two using a visual format. For example, if the child produced 'imati' for 'ikati', the ABX task may have involved these two words. One toy would 'say' the word 'imati' (Stimulus A) and another toy the word 'ikati' (Stimulus B). The child would then be asked to show which toy had said one of the words, e.g. 'imati' (stimulus X).

Appendix B is a form that could be used to administer the assessment tasks; it provides a framework to record the data from the three tasks in a manner that allows for ready administration and analysis. Items that are not named immediately default to the repetition task, and auditory discrimination items are only based on errors in the naming and repetition tasks. Data can then be transferred to Appendix C, which provides a structure for analysis based on what was done in this study.

The protocol presented here could be used to assist with clinical assessment of children with speech difficulties - when working in any language. Additional resources may be

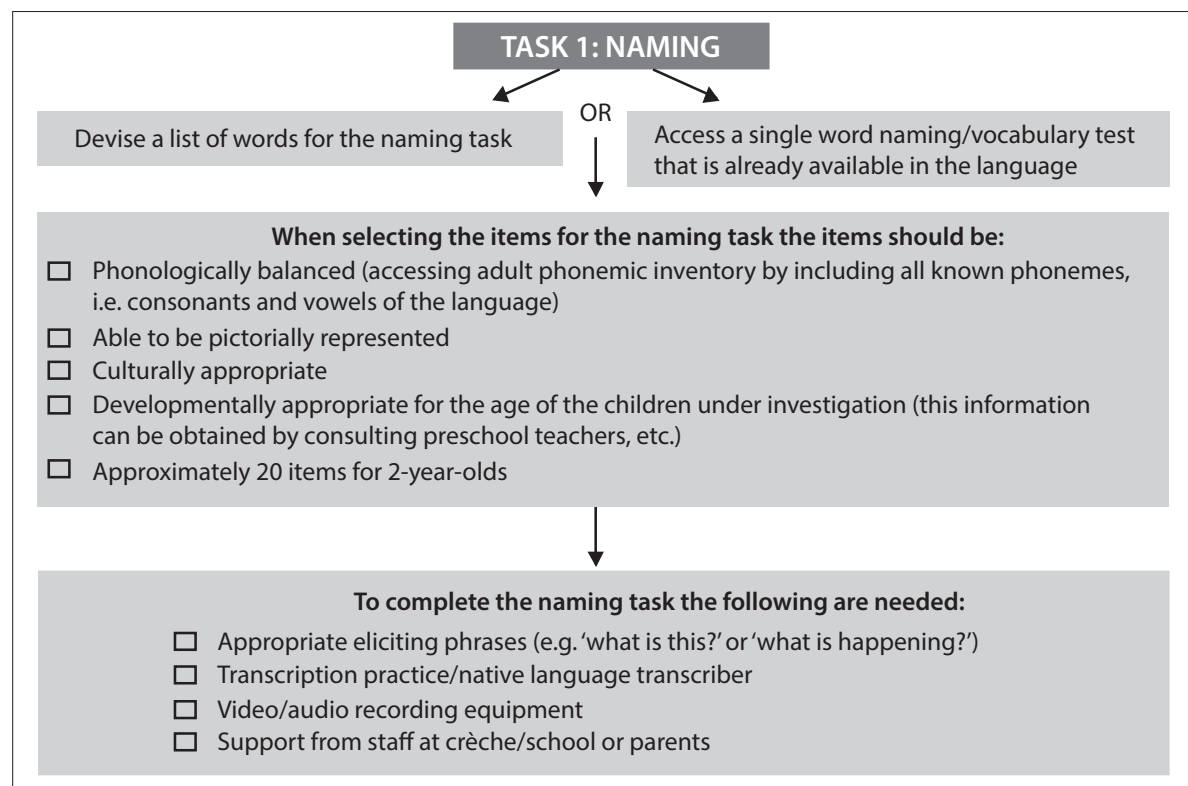

\section{TASK 2: REPETITION}

When selecting the items for the repetition task use the items chosen for the naming task.

If the target words from the naming task were not named spontaneously, they automatically become items for the repetition task.
If the target words from the naming task were named spontaneously, a period of time must pass until these items can be used in the repetition task; therefore these items can only be used in a repetition task once the auditory discrimination task has been completed.

TASK 3: AUDITORY DISCRIMINATION
Where errors occur in the repetition task, the target words that were wrongly'repeated' default and automatically become items in the auditory discrimination task. The errors made are paired with the correct target word, e.g. if the word $d o g$ is repeated as $\log$, this item should be used in the auditory discrimination task by pairing dog with $\log$ in order to identify whether the child can discriminate between /d/ and /// within words.
Fig. 1. A protocol for assessing speech processing and production in young children (from Fish et al., 2012).
The words that were produced correctly in the repetition task cannot be used as items for the auditory discrimination task. 
needed to complete the protocol, e.g. a phonetic inventory of the language in question. Using three tasks allows for more in-depth investigation of children's speech processing, stored representations and speech production skills than typical 'output only' tasks allow. Children may present with similar speech sound difficulties that reflect different underlying causes, e.g. one child may have articulation or motor programming difficulties, and another child whose speech errors appear similar may have difficulties with auditory discrimination which means that words are inappropriately stored and produced as a result of the input problems. Having detailed information about a child's speech processing, production and phonological representations may mean that if intervention is needed the SLT can make sure it is specific to the child's needs. Some children will require therapy focusing on input skills and others may need help in updating old/inaccurately stored motor programmes. It is not suggested that this is the only or even best way to undertake this work, but Fish et al. (2012) aimed to share what was done as a documented starting point. Authors such as these contribute to the development agenda of SLTs in South Africa by documenting their journey undertaken and making it available to others who may find it useful for their own research or clinical purposes.

\section{Conclusions}

In this editorial we aimed to share some of the methods that we used in research projects that have aimed to adapt or develop contextually relevant resources for the use of SLTs and As in the Western Cape region of South Africa. Delphi panels can be used in a variety of ways to meet a variety of goals. Here we gave two examples of how they could be used to assist with stimuli selection when compiling assessment or therapy tasks, and the process of translation. These panels can enhance the validity of the work undertaken in studies of cross-cultural adaptation and are well documented in the literature (Beaton, Bombardier, Guillemin \& Ferraz, 2000; Du Plessis \& Human, 2007; Keeney et al., 2011; Vernon, 2009; World Health Organization, 2012). We aimed to describe them specifically as they were used in studies focusing on SLT/A materials development in South Africa. The results of some small-scale or single-subject research may be limited in generalisability to the wider population, but we have argued that there may be much to be learned about the journey taken - even if the ultimate destination is not yet reached. The answer to the question posed in our title is probably 'No' - we have some way to go in our development of culturally and linguistically appropriate materials for use with all of the people with communication difficulties in our country. However, the journal shows that we are moving forward towards this goal. Small projects, undertaken by clinicians in response to their dayto-day needs, and the work of undergraduate students in their clinics, assignments and research projects, need to be 'out there' for all to see, share and learn from. Documenting the steps taken, such as the protocol of Fish et al. (2012), is one way in which a small-scale study can make a potentially bigger impact.

Acknowledgements. Thanks to Anita Edwards for managing the peer review of this paper, and to the peer reviewers for their helpful comments. Thanks to our undergraduate student groups who contributed to some of the work we describe; Zinhle Maphalala and Mantoa Smouse for their key roles in much of the isiXhosa work described here, and Shajila Singh who was involved in discussions which led to this paper.

M Pascoe, PhD; C Rogers, MSc Audiology;

V Norman, M Communication Pathology

Department of Health and Rehabilitation Sciences, University of Cape Town

Barrat, J., Khoza-Shangase, K. \& Msimang, K. (2012). Speech-language assessment in a linguistically diverse setting: Preliminary exploration of the possible impact of informal 'solutions' within the South African context. South African Journal of Communication Disorders, 59, 34-44. doi:10.7196/SAJCD.57
Beaton, D. E., Bombardier, C., Guillemin, F., \& Ferraz, M. B. (2000). Guidelines for the process of cross-cultural adaptation of self-report measures. Spine, 25 (24), 3186-3191. Cialkowska, M., Adamowski, T., Piotrowski, P. \& Kiejna, A. (2008). What is the Delphi method? Strengths and shortcomings. Psychiatr Pol, 42 (1), 5-15.

Du Plessis, E. \& Human, S. P. (2007). The art of the Delphi technique: highlighting its scientific merit. Health Gesondheid, 12, 13-24.

Fish, L., Jansen, C., Manley, N., Powell, M., Pratt, K. \& Rosen, L. (2012). Speech processing and production in two-year old children acquiring isiXhosa: A description of three cases. Unpublished Undergraduate Thesis. University of Cape Town.

Glasgow, R. \& Riley, W. (2013). Pragmatic Measures: What they are and why we need them? Am J Prev Med, 45(2), 237-243.

Kathard, H., Naude, E., Pillay, M. \& Ross, E. (2007). Improving the relevance of speechlanguage pathology and audiology research and practice. South African Journal of Communication Disorders, 54, 5-7.

Keeney, S., Hasson, F. \& McKenna, H. (2011). The Delphi technique in nursing and health research. Chichester: Wiley-Blackwell. doi:10.1002/978144439

Maphalala, Z. (2012). Phonological development of first language Xhosa-speaking children aged 3;0 - 5;11 years: a descriptive cross-sectional study. Unpublished Undergraduate Thesis. University of Cape Town.

Maphalala, Z., Pascoe, M. \& Smouse, M. (2013). Phonological development of first language isiXhosa-speaking children aged 3;0 - 6;0 years: a descriptive crosssectional study. Clinical Linguistics and Phonetics, Early Online: 1-19. doi: 10.3109/02699206.2013.840860.

McLeod, S., Verdon, S., Bowen, C. \& the International Expert Panel on Multilingual Children's Speech. (2013). International aspirations for speech-language pathologists' practice with multilingual children with speech sound disorders: Development of a position paper. Journal of Communication Disorders, 46: 375-387.

Mokkink, L. B., Terwee, C. B., Patrick, D. L., Alonso, J., Stratford, P. N., et al. (2010). The COSMIN study reached international consensus on taxonomy, terminology and definition of measurement properties for health-related patient reported outcomes. J Clin Epidemiol, 63, 737-745.

Pascoe, M. \& Norman, V. (2011). Contextually relevant resources in speech-language therapy and audiology in South Africa - are there any? South African Journal of Communication Disorders, 58, 2-5.

Penn, C. (1998). The study of child language in South Africa. Folia PhoniatriLogop, 50, 256-270.

Penn, C. (2007). 'Don't give me the theory, just tell me what to do in therapy!': The slippery slope challenge for the South African professions of speech-language pathology and audiology. South African Journal of Communication Disorders, 54, 13-17.

Powell, C. (2003). The Delphi technique: myths and realities. J Adv Nurs, 41(4), 376-382.

Rogers, C., de Wet, J., Gina, A., Louw, L., Makhoba, M., \& Tacon, L. (2011). The translation of the Vertigo Symptom Scale into Afrikaans: A pilot study. South African Journal of Communication Disorders, 58, 6 - 12.

Rescorla, L. (1989). The Language Development Survey: A screening tool for delayed language in toddlers. Journal of Speech and Hearing Disorders, 54, 587-599.

Sousa, V. \& Rojjanasrirat, W. (2011). Translation, adaption and validation of instruments or scales for use in cross-cultural health care research: a clear and user-friendly guideline. Journal of Evaluation in Clinical Practice, 17, 268 - 274.

Southwood, F. \& van Dulm, O. (2012). Receptive and expressive activities in language therapy (REALT). Johannesburg: JvR Psychometrics.

Southwood, F. \& van Dulm, O. (2013). Child language assessment and intervention in a multilingual context: The state of the art in the rainbow nation. Paper presented at SASLHA Conference, Bloemfontein, September 2013. http://www.entcongress.co.za/ images/2013Presentations/Venue3/30th/14h30southwoodvandulmvenue3monday.pdf

Stackhouse, J. \& Wells, B. (1997). Children's speech and literacy difficulties I: A psycholinguistic framework. London: Whurr Publishers.

Stackhouse, J. \& Wells, B. (2001). Children's speech and literacy difficulties II: Identification and intervention. London: Whurr Publishers.

Suleiman, K. H. \& Yates, B. C. (2011). Translating the Insomnia Severity Index into Arabic. J Nurs Scholarsh, 43, 49-53.

Swanepoel, D. (2006). Audiology in South Africa. International Journal of Audiology, 45, 262-266.

Vance, M. \& Clegg, J. (2012). Use of single case study research in child speech, language and communication interventions. Editorial Introduction. Child Language Teaching and Therapy, 28(3) 255-258.

Vernon, W. (2009). The Delphi technique: A review. International Journal of Therapy and Rehabilitation, 16 (2):69-76

World Health Organization. (2012). Process of translation and adaptation of instruments. Retrieved on 22 November 2012 from http://www.who.int/substance_abuse/research_ tools/translation/en/

Yardley, l., Masson, E., Verschuur, L., Haacke, N. \& Luxon, L. (1992). Symptoms, anxiety and handicap in dizzy patients: development of the Vertigo Symptom Scale. J Psychosom Res, 36, 731-741. 


\section{Appendix A. Questionnaire for panel 2, translation and validation of the Vertigo Symptom Scale}

Likert scale responses varied from 1:'I strongly agree' to 5:'I do not agree at all'. After each item, space was allowed for participants to enter feedback under the following headings: comment, suggestions and items that are problematic.

\begin{tabular}{|c|c|c|}
\hline Statement for consensus & $\begin{array}{c}\text { Likert score } \\
1-5\end{array}$ & Feedback \\
\hline \multicolumn{3}{|l|}{$\begin{array}{l}\text { This translation is incomplete } \\
\text { All the items in the translated AVSS cover the same content as the VSS }\end{array}$} \\
\hline \multicolumn{3}{|l|}{ The translated AVSS captures the essence of the original VSS } \\
\hline \multicolumn{3}{|l|}{ The phrasing of the questionnaire captures accurately the true feeling of vertigo } \\
\hline \multicolumn{3}{|l|}{$\begin{array}{l}\text { Some items need to be reworded in order to be more representative of the } \\
\text { original VSS }\end{array}$} \\
\hline \multicolumn{3}{|l|}{ The AVSS is an appropriate translation for mother-tongue Afrikaans speakers } \\
\hline \multicolumn{3}{|l|}{$\begin{array}{l}\text { I feel item number/s ... of the translated version accurately represent/s its } \\
\text { original form in the VSS }\end{array}$} \\
\hline \multicolumn{3}{|l|}{$\begin{array}{l}\text { If I had translated item .... into Afrikaans myself it would be the same/similar to } \\
\text { the translation given }\end{array}$} \\
\hline \multicolumn{3}{|l|}{$\begin{array}{l}\text { The translated scale is capable of gaining appropriate responses and can } \\
\text { differentiate between those with vertigo and those without }\end{array}$} \\
\hline \multicolumn{3}{|l|}{$\begin{array}{l}\text { I feel that the level of language used is appropriate for the Afrikaans client } \\
\text { population I usually work with }\end{array}$} \\
\hline \multicolumn{3}{|l|}{ Do you think that ' $n$ aantal ure is an appropriate translation of 'a few hours'? } \\
\hline \multicolumn{3}{|l|}{ For response 2 , etlike kere is a better translation for 'several times' than ' $n$ paar keer } \\
\hline \multicolumn{3}{|l|}{ Do you think that duiseligheid is an appropriate translation for vertigo? } \\
\hline \multicolumn{3}{|l|}{$\begin{array}{l}\text { Do you think that the English term vertigo should stay the same in the Afrikaans } \\
\text { translation? }\end{array}$} \\
\hline \multicolumn{3}{|l|}{ You would translate 'unsteadiness' as onstandvastigheid (item 4) } \\
\hline \multicolumn{3}{|l|}{$\begin{array}{l}\text { Would you use ligsinnigheid in place of duiseligheid as a translation for giddy? } \\
\text { (item 7) }\end{array}$} \\
\hline \multicolumn{3}{|l|}{$\begin{array}{l}\text { Do you think that dofheid appropriately captures the essence of blurring in } \\
\text { vision? (item 13) }\end{array}$} \\
\hline \multicolumn{3}{|l|}{ Kortasem is a better translation of 'short of breath' than uit asem uit (item 16) } \\
\hline \multicolumn{3}{|l|}{$\begin{array}{l}\text { Does drukking substantially approximate the sensation of aural fullness, i.e. } \\
\text { pressure in the ear? (item 9) }\end{array}$} \\
\hline \multicolumn{3}{|l|}{$\begin{array}{l}\text { 'A feeling that things are spinning or moving around' is adequately translated } \\
\text { through 'n gevoel dat alles draai of in die rondte beweeg (item 1). }\end{array}$} \\
\hline \multicolumn{3}{|l|}{$\begin{array}{l}\text { The feeling of the onset of a loss of consciousness is well represented by besig } \\
\text { om bewussyn te verloor (item 22). }\end{array}$} \\
\hline \multicolumn{3}{|l|}{$\begin{array}{l}\text { A patient who reads swewing will make the association with 'a feeling of } \\
\text { swimming, floating or soaring' (item 7) }\end{array}$} \\
\hline \multicolumn{3}{|l|}{$\begin{array}{l}\text { Will someone who reads this translation understand warm of koue voorvalle } \\
\text { to mean the same as 'hot or cold spells'? (item 3) }\end{array}$} \\
\hline \multicolumn{3}{|l|}{$\begin{array}{l}\text { A patient would understand spanning to be a question of whether they } \\
\text { experience tension (item 6) }\end{array}$} \\
\hline \multicolumn{3}{|l|}{$\begin{array}{l}\text { Rillings adequately conveys the fundamental nature of the experience of } \\
\text { shivering (item 8) }\end{array}$} \\
\hline \multicolumn{3}{|l|}{ Jy or jou are better words to use than $U$ in this Afrikaans scale } \\
\hline \multicolumn{3}{|l|}{$\begin{array}{l}\text { Hartkloppings of versnellings appropriately conveys the idea of a heart rate that } \\
\text { has increased, such that the patient will describe it as 'pounding' or 'fluttering' } \\
\text { (item 10) }\end{array}$} \\
\hline \multicolumn{3}{|l|}{$\begin{array}{l}\text { Is 'n naar gevoel op die maag an appropriate translation of 'stomach churning'? } \\
\text { (item 5) }\end{array}$} \\
\hline \multicolumn{3}{|l|}{$\begin{array}{l}\text { Do you think geheue will be interpreted as 'memory' by someone who reads this } \\
\text { scale? (item 17) }\end{array}$} \\
\hline \multicolumn{3}{|l|}{ Neerval better approximates 'falling' than oorval (item 4) } \\
\hline $\begin{array}{l}\text { A patient would understand besig om balans te verloor as 'about to lose } \\
\text { balance' (item 18) }\end{array}$ & & \\
\hline
\end{tabular}


Appendix B. Response form for assessing speech processing and production in young children

\begin{tabular}{|c|c|c|c|c|c|c|c|c|}
\hline \multirow{2}{*}{\multicolumn{5}{|c|}{$\begin{array}{l}\text { Child's name: } \\
\text { Age: }\end{array}$}} & \multirow{2}{*}{\multicolumn{4}{|c|}{$\begin{array}{l}\text { Date: } \\
\text { Language: }\end{array}$}} \\
\hline & & & & & & & & \\
\hline & \multirow{2}{*}{ Naming target } & \multirow{2}{*}{$\begin{array}{l}\text { Participant's } \\
\text { response } \\
\text { (IPA transcription) }\end{array}$} & \multirow{2}{*}{$\begin{array}{c}* \sqrt{ } / \mathrm{X} / \\
\mathrm{NA}\end{array}$} & \multirow{2}{*}{$\begin{array}{l}\text { Repetition - } \\
\text { participant's response } \\
\text { (IPA transcription) }\end{array}$} & \multirow[t]{2}{*}{$* \sqrt{ } / \mathrm{X}$} & \multicolumn{2}{|c|}{ Auditory discrimination } & \multirow[t]{2}{*}{$* \sqrt{ } / \mathrm{x}$} \\
\hline & & & & & & Error & Target & \\
\hline 1. & e.g. ball & $/ b \supset: /$ & $\sqrt{ }$ & /bכ:/ & $\sqrt{ }$ & & & \\
\hline 2. & e.g. dog & lgog/ & $x$ & lgog/ & $x$ & lgog/ & $/ d o g /$ & $x$ \\
\hline 3. & e.g. tree & Not named & $N A$ & /twi:/ & $x$ & /twi:/ & /tri:/ & $\sqrt{ }$ \\
\hline \multicolumn{9}{|l|}{4.} \\
\hline \multirow{2}{*}{\multicolumn{9}{|c|}{$\begin{array}{l}5 . \\
6 .\end{array}$}} \\
\hline & & & & & & & & \\
\hline \multicolumn{9}{|l|}{7.} \\
\hline \multicolumn{9}{|l|}{8.} \\
\hline \multirow{2}{*}{\multicolumn{9}{|c|}{9.}} \\
\hline \multirow{2}{*}{\multicolumn{9}{|c|}{10.}} \\
\hline & & & & & & & & \\
\hline \multicolumn{9}{|c|}{12.} \\
\hline \multicolumn{9}{|c|}{13.} \\
\hline \multirow{2}{*}{\multicolumn{9}{|c|}{14.}} \\
\hline \multirow{2}{*}{\multicolumn{6}{|c|}{15.}} & & & \\
\hline & & & & & & & & \\
\hline \multicolumn{9}{|c|}{17.} \\
\hline \multicolumn{9}{|c|}{18.} \\
\hline \multicolumn{9}{|c|}{19.} \\
\hline 20. & & & & & & & & \\
\hline * & icipant got the target $\mathrm{i}$ & X-participant & et item incorrect & NA - not attempted (do imita & diately) & & & \\
\hline
\end{tabular}

\section{Appendix C. Analysis sheet for assessing speech processing and production in young children}

Naming and Repetition

As part of the independent analysis, identify which phonemes (i.e. consonants and vowels) are present in the child's inventory, by circling the phonemes present in the words the child spontaneously produces (naming task) and repeats (repetition task).

\begin{tabular}{|c|c|c|c|c|c|c|c|}
\hline & \multicolumn{3}{|l|}{$\begin{array}{l}\text { Child's name: } \\
\text { Age: }\end{array}$} & \multicolumn{4}{|c|}{$\begin{array}{l}\text { Date: } \\
\text { Language: }\end{array}$} \\
\hline & \multirow{2}{*}{ Naming target } & \multirow{2}{*}{$\begin{array}{l}\text { Participant's response } \\
\text { (IPA transcription) }\end{array}$} & \multirow{2}{*}{ Phonemes identified } & \multicolumn{3}{|c|}{ Position in the word } & \multirow{2}{*}{$\begin{array}{l}\text { Number of syllables present and } \\
\text { syllable shape if applicable }\end{array}$} \\
\hline & & & & Initial & Medial & Final & \\
\hline \multirow{7}{*}{$\frac{\text { ס }}{\frac{\text { ह }}{\text { ह }}}$} & e.g. ball & /bכ:/ & b & $\checkmark$ & & & $1 \mathrm{cvc}$ \\
\hline & & & J: & & $\checkmark$ & & \\
\hline & & & 1 & & & & \\
\hline & e.g. louder & /laudə/ & I & & & $\checkmark$ & $2 \mathrm{cvcv}$ \\
\hline & & & au & $\checkmark$ & & & \\
\hline & & & d & & $\checkmark$ & & \\
\hline & & & $\partial$ & & $\checkmark$ & & \\
\hline
\end{tabular}

\begin{tabular}{|c|c|c|c|c|c|c|c|}
\hline & \multicolumn{3}{|l|}{$\begin{array}{l}\text { Child's name: } \\
\text { Age: }\end{array}$} & \multicolumn{4}{|c|}{$\begin{array}{l}\text { Date: } \\
\text { Language: }\end{array}$} \\
\hline & \multirow{2}{*}{ Repetition target } & \multirow{2}{*}{$\begin{array}{l}\text { Participant's response } \\
\text { (IPA transcription) }\end{array}$} & \multirow{2}{*}{ Phonemes identified } & \multicolumn{3}{|c|}{ Position in the word } & \multirow{2}{*}{$\begin{array}{l}\text { Number of syllables present and } \\
\text { syllable shape if applicable }\end{array}$} \\
\hline & & & & Initial & Medial & Final & \\
\hline \multirow{7}{*}{ 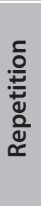 } & e.g. ball & /bo:/ & b & $\checkmark$ & & & $1 \mathrm{cvc}$ \\
\hline & & & ग: & & $\checkmark$ & & \\
\hline & e.g. louder & /laudə/ & 1 & & & $\checkmark$ & 2 gucy \\
\hline & -9. & 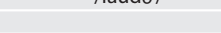 & au & $\checkmark$ & & 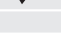 & $2 \cos$ \\
\hline & & & d & & $\checkmark$ & & \\
\hline & & & $\partial$ & & $\checkmark$ & & \\
\hline & & & & & & $\checkmark$ & \\
\hline
\end{tabular}




\section{Appendix C (continued). Analysis sheet for assessing speech processing and production in young children}

As part of the relational analysis, information regarding PCC, PVC and phonological processes should be obtained using the table format below for both tasks i.e. naming and repetition:

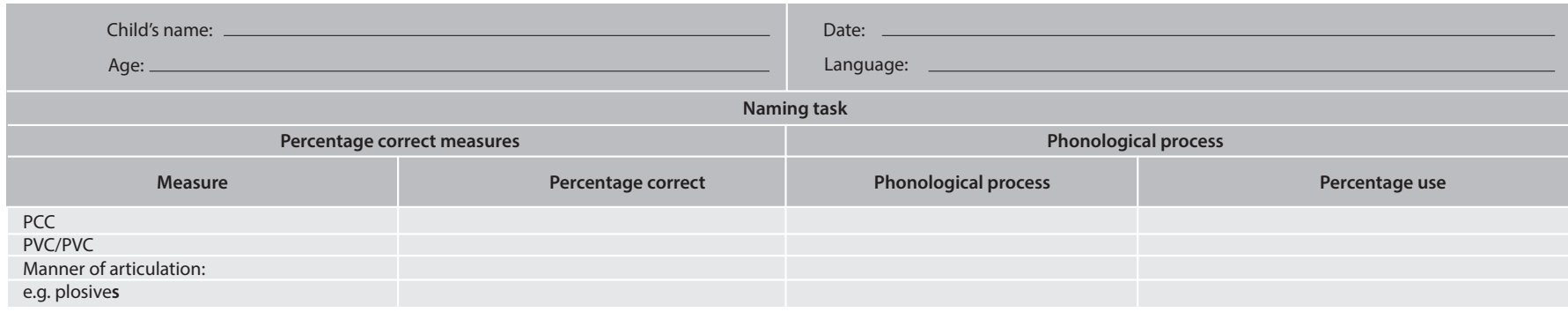

e.g. plosives

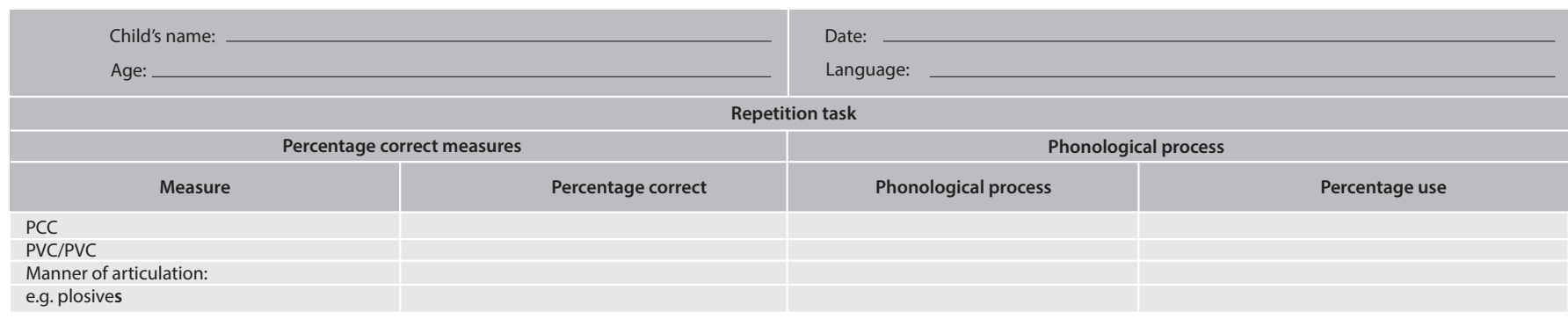

Auditory discrimination

\begin{tabular}{|c|c|c|}
\hline \multirow{2}{*}{\multicolumn{2}{|c|}{$\begin{array}{l}\text { Child's name: } \\
\text { Age: }\end{array}$}} & \multirow{2}{*}{$\begin{array}{l}\text { Date: } \\
\text { Language: }\end{array}$} \\
\hline & & \\
\hline $\begin{array}{l}\text { Paired stimuli } \\
\text { error vs. target }\end{array}$ & $\begin{array}{l}\text { Able to distinguish }(\sqrt{ }) \\
\text { Unable to distinguish }(X)\end{array}$ & ${ }^{*}$ Contrasting phonemes \\
\hline e.g. tat vs. cat & $\sqrt{ }$ & /t/ vs. /k/ \\
\hline $\begin{array}{l}\text { e.g. toor vs. door } \\
\text { e.g. gog vs. dog }\end{array}$ & $\mathrm{x}$ & /t/ vs. /d/ \\
\hline e.g.gog vs. dog & $\begin{array}{l}x \\
y\end{array}$ & /g/vs. /d/ \\
\hline e.g. сер vs. сар & $\sqrt{ }$ & le/vs./a/ \\
\hline
\end{tabular}

